\title{
FLOW INTENSIFICATION INDUCED BY TIDAL OSCILLATIONS IN TRIBUTARIES OF THE MEKONG RIVER
}

\author{
H. TAKAGI ${ }^{1}$, V. P. D. TRI ${ }^{2}$, T. V. TY ${ }^{2}$, N. D. THAO ${ }^{3}$, L. T. ANH ${ }^{3} \&$ G. V. VINH \\ ${ }^{1}$ Tokyo Institute of Technology, Japan. \\ ${ }^{2}$ University of Can Tho, Vietnam. \\ ${ }^{3}$ Ho Chi Minh City University of Technology, Vietnam. \\ ${ }^{4}$ Hydrological Center in the Cuu Long River, Vietnam.
}

\begin{abstract}
Strong currents induced by tidal oscillations have been overlooked in previous flood-risk assessments of the Mekong River. To discuss the potential disaster risk associated with tidal-flow intensification, this study applied ocean tidal modelling to a typical dry season when the tidal regime is predominant compared to the fluvial regime. The model can forecast tidal levels and velocities at a given time and location in the urban area of the Mekong Delta, which is characterized by many tributaries, channels, and low-lying lands, in addition to the main stream of the Mekong River. Numerical simulations revealed that a rapid flow, which could exceed $1 \mathrm{~m} / \mathrm{s}$ in both the ebb and flood tidal phases, likely occurred along the tributary. Although this study only focused on the tidal regime, such locally intensified flows can be further amplified by a high river discharge or storm surge, having potentially dangerous consequences, such as difficulties in handling ships and small ships being capsized.

Keywords: Can Tho city, ebb tide, flood tide, flow intensification, ocean tidal modelling, rapid flow, the Mekong Delta, the Mekong River, tributary.
\end{abstract}

\section{INTRODUCTION}

The Mekong River flows southward, covering a distance of approximately 4,800 km from its source to the sea, and draining a total catchment area of 795,000 $\mathrm{km}^{2}$ that falls within six different countries: China, Myanmar, Lao PDR, Thailand, Cambodia, and Vietnam. The Mekong River ranks 10th among the rivers of the world, on the basis of its mean annual flow at the river mouth [1]. The Mekong Delta begins at Phnom Penh, Cambodia, where the river divides into its two main distributaries: the Mekong and the Bassac. The Mekong then divides into six main channels and the Bassac divides into three, forming the delta, which is made up of a vast triangular plain of approximately $55,000 \mathrm{~km}^{2}$ [1].

The present paper highlights Can Tho City, which is the regional capital and has the highest population in the Mekong Delta (approximately 1.2 million). Can Tho is surrounded by a main river (Hau River), a tributary (Can Tho River), and many canals, demonstrating a complicated river system that appears to yield complex hydraulics (Fig. 1). Takagi et al. [2] revealed that ocean tides predominantly determine the water elevation, even in Can Tho City, which is 80 $\mathrm{km}$ inland from the river mouth. Given the importance of these oceanic influences on deltaic 


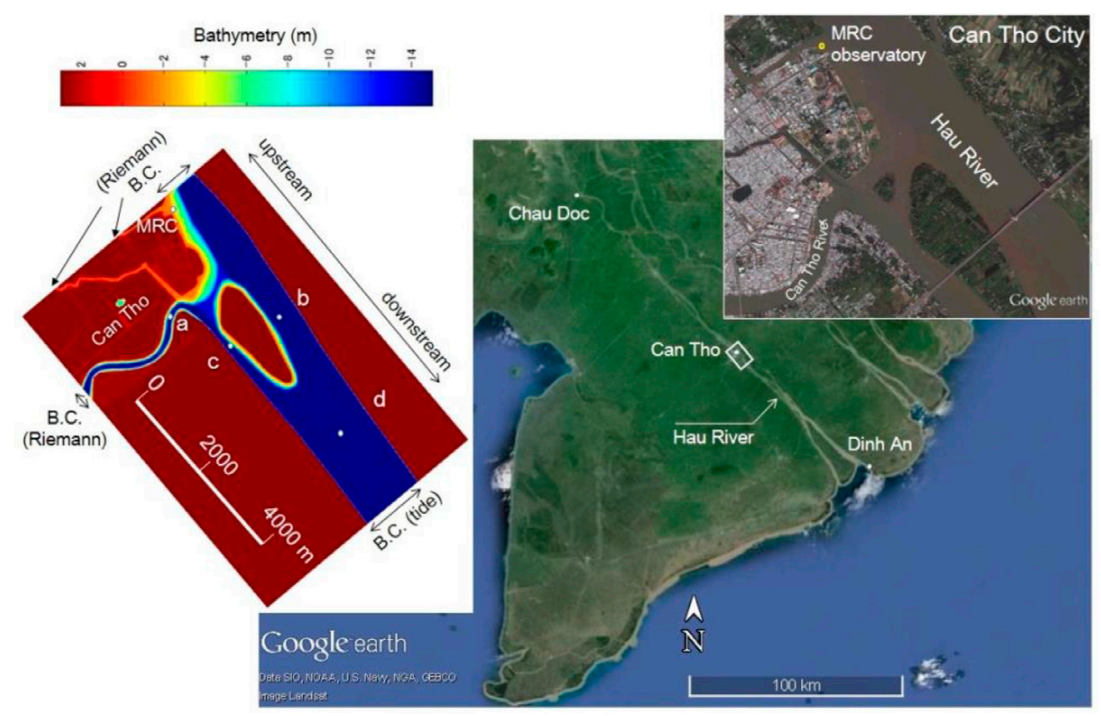

Figure 1: Can Tho, which is the largest city in the Mekong Delta, is located in southern Vietnam. The white rectangle on the satellite image indicates the computational domain used in this study, encompassing the main river (Hau River), the tributary (Can Tho River), and small canals. The frame on the left shows the domain used for the numerical simulation with open boundary conditions.

regions, Takagi et al. [3, 4] developed a tidal model and investigated the mechanisms of the tidal propagation and its influence on flooding in the urban areas of the Mekong Delta.

While numerous studies have investigated flood inundations and sea-level rise [5-8], it appears that the flow velocity during a flood was overlooked in previous flood-risk assessments of the Mekong River. Thus, to investigate the potential disaster risk associated with flow intensification, in this study, ocean tidal modelling was applied to a typical dry season when the tidal regime predominates compared to the fluvial regime.

\section{METHODOLOGIES}

The ocean tides that travel from the deep sea to the shallow waters of the continental shelf up the Hau River - and eventually flood downtown Can Tho can be simulated by Delft3D-FLOW. Although this model is applicable to a far wider region, the region is limited by the computational domain to encompass only Can Tho City and its surrounding area (Fig. 1) in order to reduce the computational cost and enable a detailed analysis of the local topography and bathymetry, which is characterized by tributaries, channels, and low-lying land. Thus, the present model may have an advantage for evaluating the detailed hydraulic characteristics within the domain.

The simulation was conducted for a typical dry season of the Mekong Delta, including the days of March 10-11, 2012, when the authors performed a field survey (Fig. 2). The computational grid size was set as $10 \mathrm{~m}$ throughout the domain. The river bathymetry data used in the computational domain were obtained by the authors by using a portable echo sounder (Fig. 1). The Manning's $n$ value was set as $0.02\left(\mathrm{~s} \mathrm{~m}^{-1 / 3}\right)$ for the riverbed and $0.05\left(\mathrm{~s} \mathrm{~m}^{-1 / 3}\right)$ for the land area [9]. 


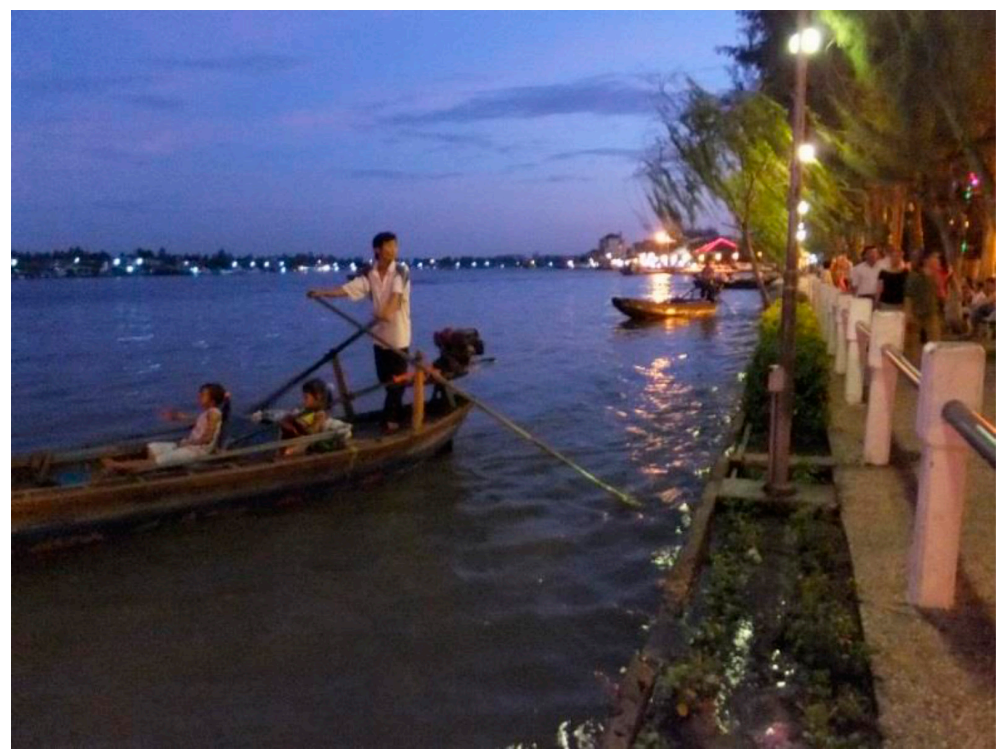

Figure 2: Photo taken by the author near point (a) on Fig. 1 at 18:30 on March 10, 2012. The tidal elevation was almost the highest for the day, demonstrating that the tidal regime is predominant in Can Tho, which is $80 \mathrm{~km}$ inland from the river mouth.

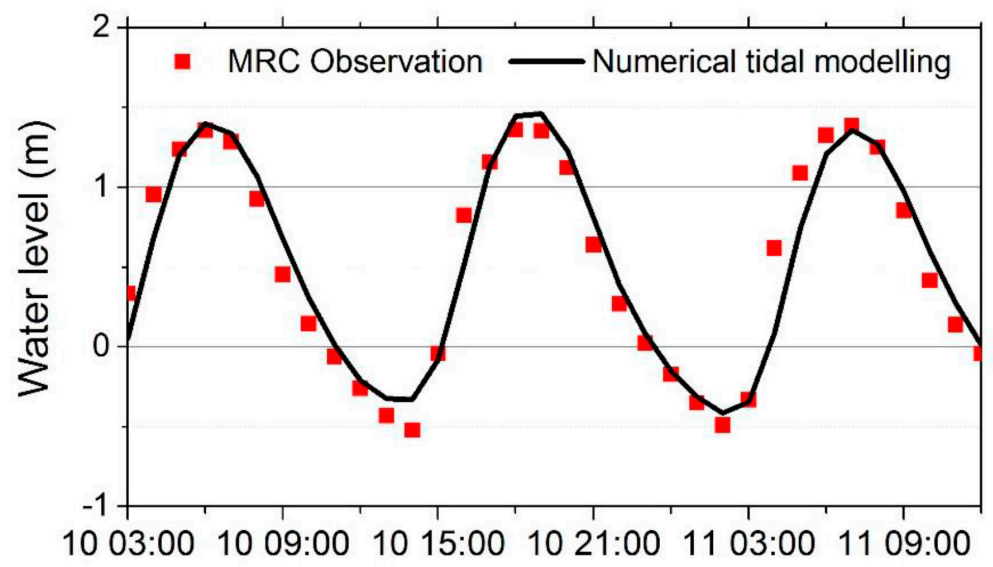

Figure 3: Comparison between the numerically simulated and measured water levels at the observatory operated by the MRC.

The tidal constituents obtained from the data at the Mekong River Commission (MRC) observatory (Fig. 1) were assigned along the downstream boundary to generate ocean tides that propagate across Can Tho. The semidiurnal and diurnal components are considered to be the factors governing the water elevation. Among all the tidal components, the semidiurnal tidal constituents with a period of approximately $12 \mathrm{~h}$ appear to have the strongest influence $[2,4]$. On the other hand, the upstream boundary and the other tributaries were set as having the Riemann condition, which enables progressive waves to pass through without reflection. 
Though there is a distance of several kilometres between the MRC observatory and the downstream boundary, it was confirmed that these obtained constituents can be used without any particular modification [4].

Figure 3 shows the tidal fluctuations at one of the output points, which is indicated as 'MRC' in Fig. 1. The simulated and observed water levels agree well, in terms of both the amplitude and phase.

\section{RESULTS AND DISCUSSION}

Figure 4 shows the simulated depth-averaged velocities at five different locations in the river basin (Fig. 1). The point referred to as 'MRC' indicates the location of the monitoring station, which is operated by the MRC. The depth-averaged velocity varied largely depending on the location in the river basin. Particularly, the flow velocity at point (a), which reached a maximum of $1.1 \mathrm{~m} / \mathrm{s}$, was almost three times that at point (d) in the main stream. Clearly, flow intensification occurred as the tidal current from the downstream river entered the narrower channels and vice versa, causing a rapid flow.

Figure 5 demonstrates that flow intensification occurred during both ebb and flood tides. In the ebb-tide phase, a strong flow developed in the tributary (Can Tho River), impinged on the sandbank, and then split into two streams, merging again approximately $2.5 \mathrm{~km}$ downstream (Fig. 5a). Interestingly, in the slack-tide phase, when the tidal current almost ceased, two whirlwinds developed near the edge of the sandbank, indicating that the tide was about to reverse its direction (Fig. 5b). In the flood-tide phase, the tide from the sea propagated upstream, and part of the water departed from the main stream and flowed into the narrower tributary, causing a rapid flow (Fig. 5c).

Typically, the maximum tidal velocity in spring tide may not exceed $1 \mathrm{~m} / \mathrm{s}$ in estuaries [10]. Considering the general understanding of tidal flow, the tidal current in this particular tributary is considered to be remarkably fast. Thus, the local intensification of the flow velocity can be an important characteristic for considering the flood risk in the urban areas of the Mekong Delta. This phenomenon can be further intensified during unusually high tides or typhoon-induced storm surges [11]. Because numerous local fishermen, tourist guides, and floating-market merchants use small wooden ships (see Fig.2), there is a considerable risk that they may encounter difficulties in handling ships or risk their ships being capsized owing to these unexpected unusually rapid flows.

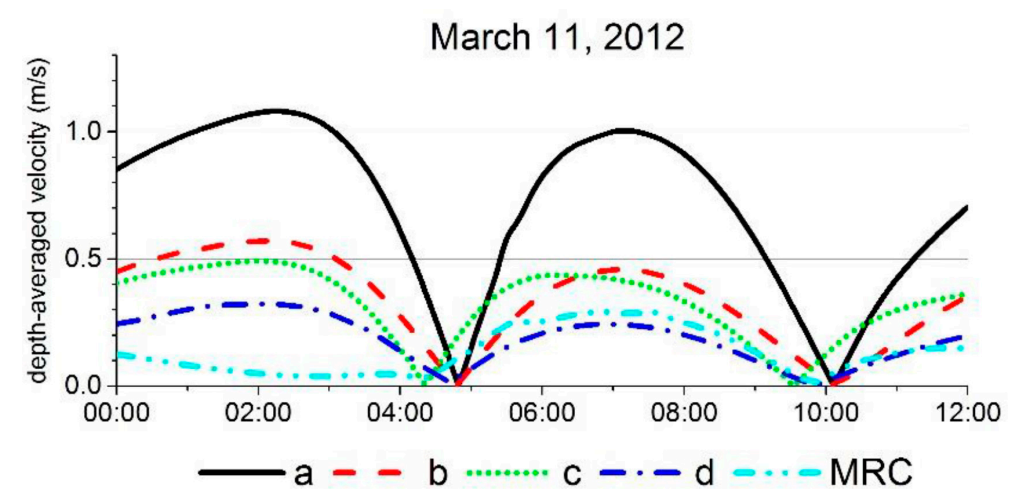

Figure 4: Simulated depth-averaged velocity during a semi-diurnal cycle in a typical dry season. The outputs correspond to the five locations indicated in Fig. 1. 


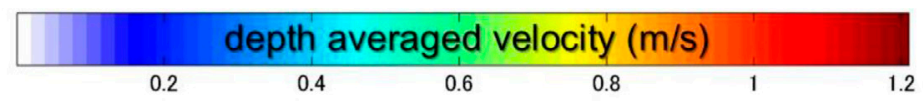

(a) March 11, 02:00
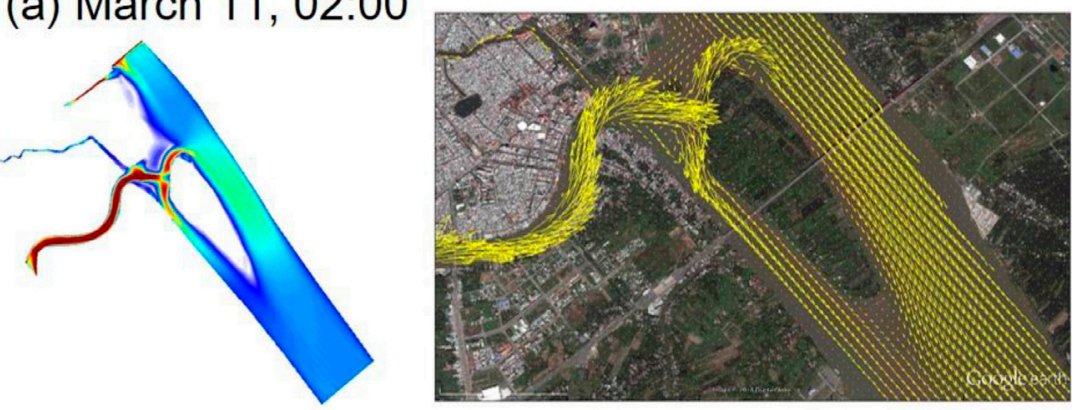

(b) March 11, 05:00
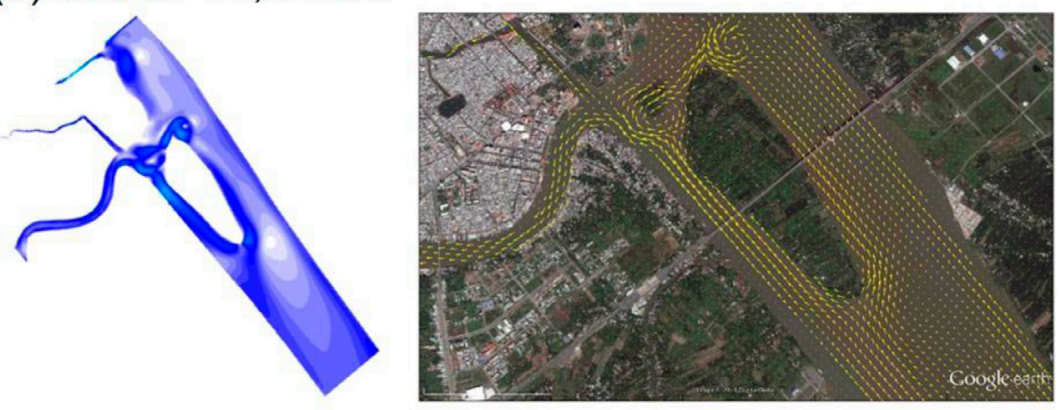

(c) March 11, 07:00
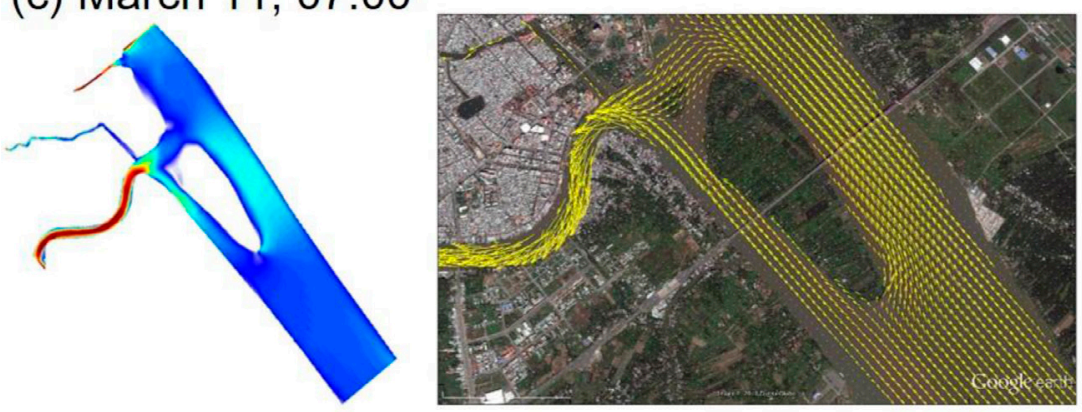

Figure 5: Tidal-flow intensification observed in the numerical simulation: (a) ebb-tide phase, (b) slack-tide phase, (c) flood-tide phase.

It is expected that the tidal currents at a given time and location can be predicted by using the model. However, it should be noted that the field survey was conducted in March, which is a typical dry season, with very limited rainfall. The weather in Vietnam is characterized by two monsoon seasons: the southwest monsoon, from April to September, and the northeast monsoon, from October to late March or early April. Southern Vietnam, including the Mekong Delta, experiences the majority of its rainfall between May and October. Therefore, the water levels in March are not significantly influenced by the discharge from upstream rivers. 
For example, in October 2013, at the end of the rainy season, numerous local communities across the delta suffered a historical flood. The water level rose to approximately $50 \mathrm{~cm}$ above the predicted tidal levels, indicating significant pluvial and fluvial influences [4]. Although Delft3D-FLOW is capable of simulating river discharge from the upstream boundary in addition to tides, the present simulation was limited to tidal forcing. Therefore, the present model cannot be used to reproduce such an abnormally high water level induced by a high river discharge. Additionally, water levels in deltas are influenced by the sea-level rise and ENSO events [12-14]. The construction of dams will inevitably alter the variability of the seasonal flow in the upper Mekong River. Furthermore, local changes driven by urbanization can significantly influence the prediction of floods in Can Tho.

\section{CONCLUSION}

Tidal modelling was applied to a complex waterway system in the Mekong Delta that is characterised by canals and tributaries, which connect with the main stream. The model, which was verified by a comparison with the observed water levels, enabled us to examine the mechanisms of tidal propagation. The model analysis indicated that the flow velocity largely varies depending on the location and the flow intensification in the tributary, which exceeds $1 \mathrm{~m} / \mathrm{s}$. This kind of local amplification in the tidal current is important for evaluating the flood/inundation risk in the urban areas of the Mekong Delta, as small ships are likely to encounter difficulties in handling or risk being capsized because of the unexpectedly rapid flows that occur during these abnormal high tides and typhoon storm surges. The findings of the present study further our understanding of the mechanisms of tidal propagation in complex waterway systems and are thus useful for identifying potential urban flood risks associated with oceanic tides.

\section{ACKNOWLEDGEMENTS}

The present research was funded by the JSPS KAKENHI (Grant Number 26702009) and The Obayashi Foundation. The authors thank, Shintaro Maeda, Yuto Takahashi, and Chiaki Tsurudome for their valuable assistance in accomplishing this study.

\section{REFERENCES}

[1] Mekong River Commission (MRC), Overview of the Hydrology of the Mekong Basin. ISSN: 1728 3248, 2005.

[2] Takagi, H., Ty, T.V., Thao, N.D. \& Esteban, M., Ocean tides and the influence of sea-level rise on floods in urban areas of the Mekong Delta. Journal of Flood Risk Management, 8, pp. 292-300, 2015. http://dx.doi.org/10.1111/jfr3.12094

[3] Takagi, H, Thao, N.D., Esteban, M., Mikami, T., Cong, L.V. \& Ca, V.T., Coastal disasters in Vietnam. In Handbook of Coastal Disaster Mitigation for Engineers and Planners, eds. Esteban, M., Takagi, H. \& Shibayama, T. Elsevier: New York, U.S., pp. 235-255. http://dx.doi.org/10.1016/B978-0-12-801060-0.00012-5

[4] Takagi, H., Tsurudome, C., Nguyen, D.T., Le, T.A., Tran, V.T. \& Van P.D.T., Ocean tidal modelling for urban flood risk assessment in the Mekong Delta. Hydrological Research Letters, 10, pp. 21-26, 2016. http://dx.doi.org/10.3178/hrl.10.21

[5] Wassmann, R., Hien, N.X., Hoanh, C.T. \& Tuong, T.P., Sea level rise affecting the Vietnamese Mekong Delta: water elevation in the flood season and implications for rice production. Climatic Change, 66, pp. 89-107, 2004. 
http://dx.doi.org/10.1023/B:CLIM.0000043144.69736.b7

[6] Carew-Reid, J., Rapid assessment of the extent and impact of sea level rise in Viet Nam. Climate Change Discussion Paper 1, ICEM -International Centre for Environmental Management, 82, 2008.

[7] Takagi, H., Ty, T.V. \& Thao, N.D., Investigation on floods in Can Tho City: influence of ocean tides and sea level rise for the Mekong Delta's largest City, eds. N.D. Thao, H. Takagi \& M. Esteban. Coastal Disasters and Climate Change in Vietnam: Engineering and Planning Perspectives, pp. 257-274, 2014. http://dx.doi.org/10.1016/B978-0-12-800007-6.00012-5

[8] Yamamoto, L., Environmental displacement in Vietnam. In: D.T. Nguyen, H. Takagi \& M. Esteban. Coastal Disasters and Climate Change in Vietnam - Engineering and Planning Perspectives, Elsevier: New York, pp. 379-393, 2014. http://dx.doi.org/10.1016/b978-0-12-800007-6.00018-6

[9] Takagi, H., Li, S., de Leon, M., Esteban, M., Mikami, T., Matsumaru, R., Shibayama, T. \& Nakamura, R., Storm surge and evacuation in urban areas during the peak of a storm. Coastal Engineering, 108, pp. 1-9, 2016. http://dx.doi.org/10.1016/j.coastaleng.2015.11.002

[10] Savenije, H.H.G., A simple analytical expression to describe tidal damping or amplification. Journal of Hydrology, 243, pp. 205-215, 2001. http://dx.doi.org/10.1016/S0022-1694(00)00414-5

[11] Takagi, H., Nguyen, D.T., Esteban, M., Tran, T.T., Hanne, L.K. \& Mikami, T., Vulnerability of coastal areas in Southern Vietnam against tropical cyclones and storm surges. Proceedings of ICEC, pp. 292-299, 2012.

[12] Nguyen, D.T., Takagi, H. \& Esteban, M. (eds), Coastal Disasters and Climate Change in Vietnam -Engineering and Planning Perspectives, Elsevier: New York, U.S., p. 424, 2014, ISBN: 978-0128000076

[13] Esteban, M., Takagi, H. \& Shibayama, T., Handbook of Coastal Disaster Mitigation for Engineers and Planners, Elsevier: New York, U.S., p. 780, 2015, ISBN: 978-0-12801060-0.

[14] Takagi, H., Esteban, M., Mikami, T. \& Fujii, D., Projection of coastal floods in 2050 Jakarta, Urban Climate, Vol.17, pp. 135-145, 2016.

http://dx.doi.org/10.1016/j.uclim.2016.05.003 